\title{
Influence of substrate characteristics on single Ti splat bonding to ceramic substrates by cold spray
}

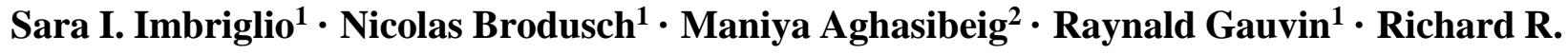
Chromik $^{1, *}$

1 Department of Mining and Materials Engineering, McGill University, 3610 University Street, Montreal, QC H3A 0C5

2 National Research Council Canada, Boucherville, QC, J4B 6Y4, Canada

* Corresponding author. Telephone: +1(514) 398-5686; Fax: +1 (514) 398-4492

Email address: richard.chromik@mcgill.ca

\begin{abstract}
The cold spray technique may be used to fabricate metal matrix composites and to metallize ceramics. Both applications involve the creation of metal/ceramic interfaces, which are well researched for other processes but not nearly as much for cold spray. Here, the effect of ceramic substrate composition and surface roughness on adhesion strength of metallic splats is investigated. Splat adhesion testing was performed on Ti splats deposited on $\mathrm{Al}_{2} \mathrm{O}_{3}$ substrates with varying average reduced peak height roughness $\left(\mathrm{R}_{\mathrm{pk}}\right)$ values. Ti splats sprayed onto $\mathrm{Al}_{2} \mathrm{O}_{3}$ with the lowest surface roughness had a higher bond strength $(305 \pm 87 \mathrm{MPa})$ than splats deposited on the higher surface roughness $\mathrm{Al}_{2} \mathrm{O}_{3}(237 \pm 47 \mathrm{MPa})$. Failed interfaces revealed that the bonding mechanism for substrates with higher surface roughness is predominantly mechanical interlocking. Adhesion to the $\mathrm{Al}_{2} \mathrm{O}_{3}$ substrate with low surface roughness is predominantly along the periphery of the particle where jetting occurs. Splat adhesion testing was also performed on Ti splats deposited on $\mathrm{SiC}$. Ti splats had a significantly higher bond strength to all $\mathrm{Al}_{2} \mathrm{O}_{3}$ substrates than to
\end{abstract}


SiC. Post-test observations of $\mathrm{SiC}$ substrates showed little evidence of bonding. Several rebounded or detached splats left traces of Ti along the periphery of the impacted particle.

Keywords titanium $\cdot$ alumina $\cdot$ silicon carbide $\cdot$ cold spray $\cdot$ interface $\cdot$ adhesion

\section{Introduction}

High pressure cold spray is a coating deposition technique by which powder is fed into a heated high-pressure gas flow and accelerated to supersonic velocities by a de Laval nozzle. The powders, accelerated to high velocity, impact on a substrate and if bonded create a 'splat'. The gas temperature is maintained below the melting temperature of the powder (Ref 1,2). Thus, for metal/metal interfaces, solid-state bonding between the powder and substrate occurs by extreme plastic deformation and the formation of adiabatic shear instabilities (ASI). Mechanical clamping and metallurgical bonding are reported for these interfaces $(\operatorname{Ref} 3,4,5)$. While a significant amount of work has been done to understand adhesion in metal/metal interfaces by cold spray, metal/ceramic interfaces are not well understood given the low deformability of the ceramic (Ref $6,7,8)$.

Two types of metal/ceramic interfaces created by cold spray are addressed in the literature. Metal matrix composites (MMC) with ceramic reinforcements have been deposited to improve adhesion, increase hardness, reduce porosity and improve tribological properties, among other advantages (Ref 2, 6, 9). Ceramic metallization by cold spray is investigated for various applications such as in the electronics industries (Ref 10,11,12,13). These coatings can also be interesting for the 
biomedical industry as Ti coatings on $\mathrm{Al}_{2} \mathrm{O}_{3}$ orthopedic implants can be specially engineered to counter issues involving the low toughness of the ceramic (Ref 14, 15).

In the deposition of MMCs, it is generally agreed that ceramic particles are embedded in coatings by the deforming metal phase with no chemical interaction (Ref $2,7,16)$. However, for metallic coatings deposited on ceramic substrates, the bonding mechanism cannot be solely attributed to mechanical clamping. Strong bonds are observed between $\mathrm{Ti}$ and $\mathrm{Al}$ coatings deposited on atomically smooth $\mathrm{Al}_{2} \mathrm{O}_{3}$ in addition to $\mathrm{Al}$ coatings deposited on $\mathrm{AlN}$ substrates (Ref 13, 17, 18). Local hetero-epitaxy was concluded to play a role in bonding between these heterogeneous materials. The kinetic energy of splats is converted to heat during plastic deformation, leading to increased atomic mobility and potential for hetero-epitaxial growth (Ref $13,17,18,19)$. Atomic mobility and intermixing of atoms at the interface has also been attributed to amorphisation at the interface during plastic deformation (Ref 20). Increased substrate temperature has been found to increase adhesion strength in metal/ceramic interfaces as it reportedly allows for a stronger chemical bond (Ref 10,11, 18, 19, 21). However, while adhesion strength varies for different types of ceramics, the influencing parameters have not been fully identified. Drehmann et al. showed that traditional trends observed between bond strength and ionicity when wetting ceramics by metals are not respected in cold spray (Ref 18). Also, the coefficient of thermal expansion mismatch was not found to directly influence bond strength. Rather, a higher thermal conductivity and thermal effusivity of the substrate was assumed to have a positive effect as the interface contact temperature is lower. With a lower contact temperature, negative effects induced by the coefficient of thermal expansion mismatch between the metal and ceramic and tensile residual stresses are reduced (Ref 22). It is still unclear how substrate surface roughness will influence the chemical interaction in these metal/ceramic interfaces as mechanical clamping can also occur and if strong 
bonds are formed at a single site of impact or if adhesion is promoted by further compaction from the impact of succeeding splats. On the one hand, cross-sectional micrographs have shown gapping in the interface of $\mathrm{Al}$ single splats deposited on APS-sprayed $\mathrm{Al}_{2} \mathrm{O}_{3}$ substrates but full $\mathrm{Al}$ coatings on sintered $\mathrm{Al}_{2} \mathrm{O}_{3}$ appeared continuous (Ref 19). On the other hand, Ti single splat deposited on zirconia only showed gaping near the center of the particle and bonding near the edge (Ref 23).

In this work, single splats of Ti are deposited on $\mathrm{Al}_{2} \mathrm{O}_{3}$ and $\mathrm{SiC}$ substrates. Ti has previously shown promising dense coatings with good adhesion to $\mathrm{Al}_{2} \mathrm{O}_{3}$ deeming further investigation (Ref 17). The ceramics were selected as they are commonly found in MMCs (Ref 6, 7, 24, 25, 26). The effect of substrate composition on adhesion strength is addressed and the influence of surface roughness on adhesion in the $\mathrm{Ti} / \mathrm{Al}_{2} \mathrm{O}_{3}$ interface is investigated.

To measure bond strength, a splat adhesion test is used. This test, also referred to as a modified ball bond shear test, was introduced by Chromik et al. and later used by Goldbaum et al. (Ref 27, 28). Traditional testing techniques, such as DIN EN 582 or ASTM C-633-99, focus on full coating adhesion (Ref 19,27). The splat adhesion test was designed for analysis of bonding at the first site of impact in the splat/substrate interface. By splat adhesion testing, significantly less material is used and fracture of the ceramic as well as the epoxy under tension is avoided (Ref 27, 28). Following splat adhesion testing, the failed interface was analysed through light microscopy and scanning electron microscopy (SEM) to understand the bonding mechanism and the influence of the ceramic surface characteristics. Splat/substrate cross-sections were also studied to understand the interface morphology and bond formation. 


\section{Experimental Procedure}

Single splats of spherical, commercially pure, Ti (Grade 1, AP\&C, Quebec, Canada) were deposited onto high purity sintered $\mathrm{Al}_{2} \mathrm{O}_{3}$ and $\mathrm{SiC}$ (AD-995, SC-30, CoorsTeK, Arkansas, USA) substrates. The CP-Ti powder has a size distribution of 0 to $45 \mu \mathrm{m}$. Figure 1(a) and (b) show the powder size distribution and morphology. By laser diffraction particle size analysis (LA-920, Horiba, Kyoto, Japan), the mean particle size is $29 \mu \mathrm{m}$. The Ti powder is dense with a martensitic microstructure as shown through electron channelling contrasts (ECC) (Fig. 1 (c)).
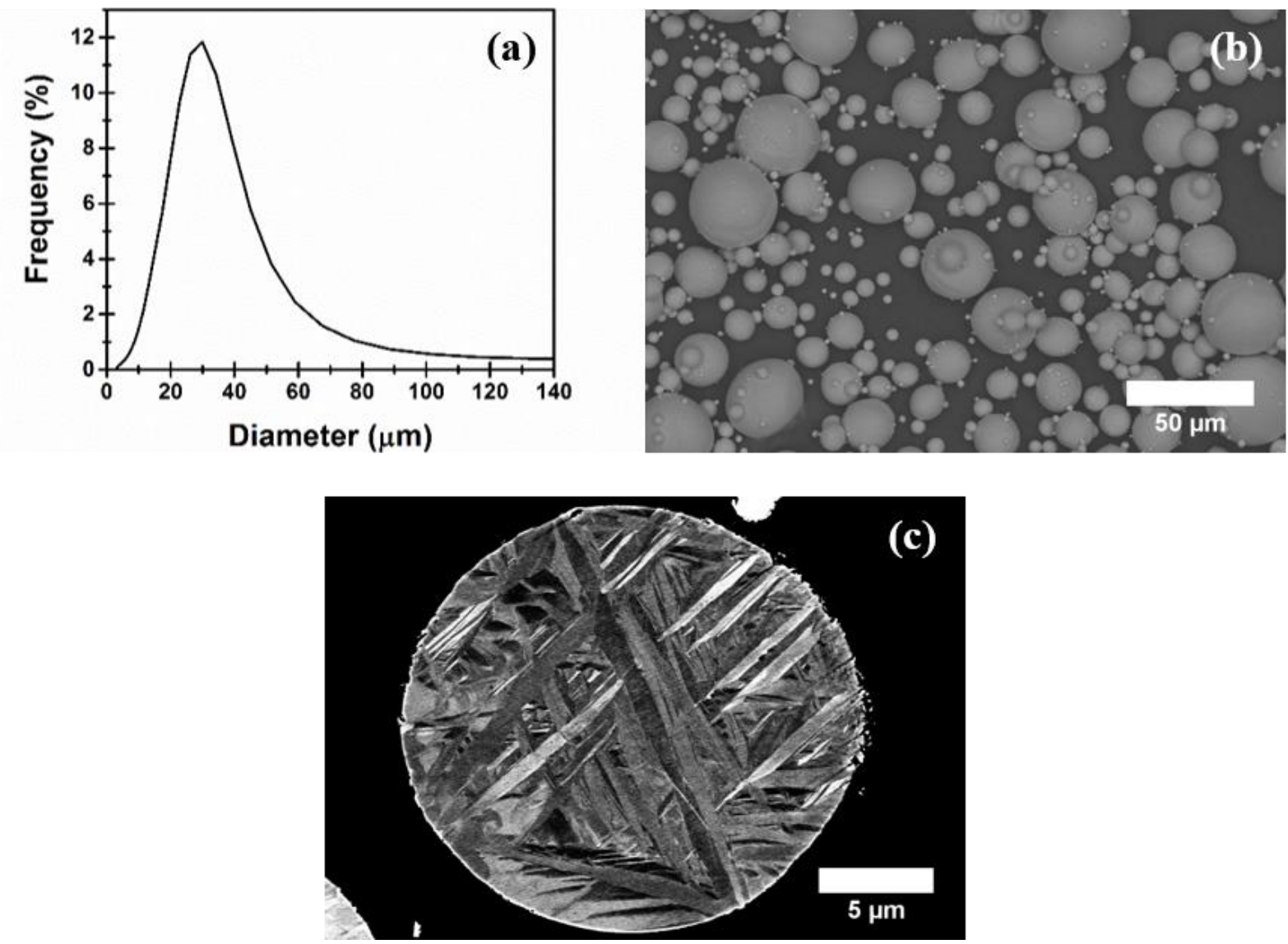

Fig. 1 The (a) powder size distribution, (b) powder morphology and (c) microstructure of the Ti powder. 
The polycrystalline and sintered $\mathrm{Al}_{2} \mathrm{O}_{3}$ and $\mathrm{SiC}$ substrates had a thickness of approximately $12.7 \mathrm{~mm}$. Figure 2 shows the as-received surface morphology of the substrates. Both substrates have a significant variation in grain size and grain morphology. The grains used in the sintering of $\mathrm{SiC}$ substrates are mostly smaller than those used to produce the $\mathrm{Al}_{2} \mathrm{O}_{3}$ substrates. Data from the manufacturer showed an average crystal size of $6 \mu \mathrm{m}$ for the $\mathrm{Al}_{2} \mathrm{O}_{3}$ and 3 to $10 \mu \mathrm{m}$ for the $\mathrm{SiC}$ samples.
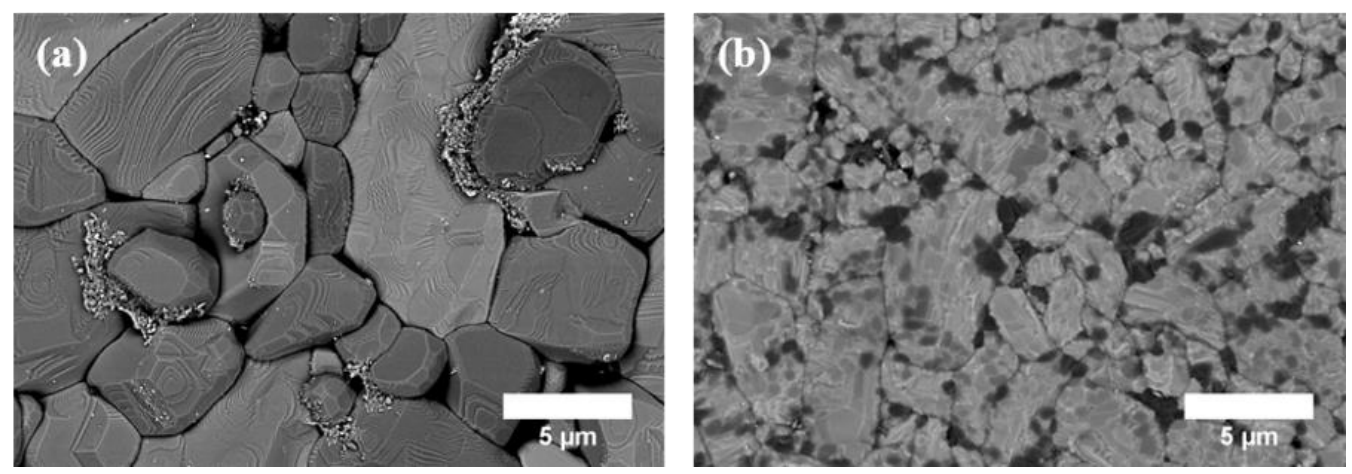

Fig. 2 A representative backscattered SEM image of the morphology and grain size of the asreceived (a) $\mathrm{Al}_{2} \mathrm{O}_{3}$ and (b) $\mathrm{SiC}$ substrates

The chemistry of the substrates was characterised through energy-dispersive X-ray spectroscopy (EDS) in the SEM (SU-8230, Hitachi, Tokyo, Japan). Charging effects were reduced by using low accelerating voltages of 3 to $5 \mathrm{kV}$. A 3D Optical Surface Profiler (ZYGO, Connecticut, USA) was also used to measure surface roughness on $3 \times 3 \mathrm{~mm}^{2}$ and $87 \mathrm{x} 87 \mu \mathrm{m}^{2}$ surface areas. Measurements were taken at two magnifications to determine the average roughness of the substrates and the local roughness at a length scale more similar to the size of a single splat. The reduced peak height value $\left(\mathrm{R}_{\mathrm{pk}}\right)$ was used to characterize surface roughness as it is a better measure for sintered materials than $R_{a}$ or $R_{k}$ to reduce the effect of porosity. $R_{p k}$ is the average height of peaks above the height of the core surface ( $\mathrm{R}_{\mathrm{k}}$ value) (Ref 29). Twelve areas on three as-received $\mathrm{Al}_{2} \mathrm{O}_{3}$ and SiC substrates were analysed to determine the average surface roughness of the substrates used. 
Given a relatively high surface roughness of $\mathrm{Al}_{2} \mathrm{O}_{3}$ in comparison to $\mathrm{SiC}$ (Table 1), six halves of the $\mathrm{Al}_{2} \mathrm{O}_{3}$ substrates were polished to a final step of $60 \mu \mathrm{m}$ diamond grinding disk and the other six halves were polished to a final step of $1 \mu \mathrm{m}$ diamond suspension. Twelve areas on the six grinded and polished substrates were analysed to obtain the average $R_{p k}$ value for these processed substrates. Average $R_{\mathrm{pk}}$ values measured by optical profilometry and sample identification used in the following sections of this work are shown in Table 1.

Table 1 Sample Roughness and Identification

\begin{tabular}{ccc}
\hline Sample & $\mathrm{R}_{\mathrm{pk}}, \mu \mathrm{m}$ & Identification \\
\hline As-received $\mathrm{Al}_{2} \mathrm{O}_{3}$ & $0.78 \pm 0.38$ & $\mathrm{Al}_{2} \mathrm{O}_{3}(0.78)$ \\
$60 \mu \mathrm{m}$ diamond grinding of $\mathrm{Al}_{2} \mathrm{O}_{3}$ & $0.33 \pm 0.07$ & $\mathrm{Al}_{2} \mathrm{O}_{3}(0.33)$ \\
$1 \mu \mathrm{m}$ diamond suspension polishing of $\mathrm{Al}_{2} \mathrm{O}_{3}$ & $0.16 \pm 0.03$ & $\mathrm{Al}_{2} \mathrm{O}_{3}(0.16)$ \\
As-received $\mathrm{SiC}$ & $0.39 \pm 0.06$ & $\mathrm{SiC}$ \\
\hline
\end{tabular}

The Ti powder was deposited on both ceramics by cold spray (PCS-800, Plasma Giken, Saitama, Japan). Nitrogen was used as the carrier gas with a pressure of $4 \mathrm{MPa}$ and a temperature of $800{ }^{\circ} \mathrm{C}$. To deposit scattered single splats, the gun traverse speed was $1 \mathrm{~m} / \mathrm{s}$. The standoff distance was set to $30 \mathrm{~mm}$. Once the feed rate was stable, the powder feeder was shut before scanning the surface of the substrate by the cold spray gun mounted on a robotic arm. As a result, only the powder that remained in the gas stream was available for deposition. This was done to ensure a population of splats that was appropriate for splat adhesion testing. Splats must be sufficiently far from one another in order to scratch single splats during splat adhesion testing.

Splat adhesion testing was conducted using a Micro-Combi Scratch Tester (CSM Instruments, Inc, Massachusetts, USA) in accordance with the testing methodology described by Chromik et al. and 
Goldbaum et al. (Ref 27, 28). In this test, the flat face of a semi-circular stylus, $100 \mu \mathrm{m}$ long, is used to shear single splats (Fig. 3). A normal force between 30 and $100 \mathrm{mN}$ is applied to maintain contact between the stylus and the substrate. In a small number of tests, the stylus traveled fully or partially above the splat and these tests were disregarded in the analysis. A scratch length of $130 \mu \mathrm{m}$ or $100 \mu \mathrm{m}$ was used depending on the available space between splats. The splat is positioned approximately at the center of the scratch length. The scratch speed was set to $150 \mu \mathrm{m} / \mathrm{min}$.

The splat adhesion test outputs a plot of tangential force applied on the stylus with respect to the scratch length. Baseline tangential force due to friction along the substrate and a peak tangential force due to the removal of the splat are recorded. Some Ti splats deposited on SiC rendered no distinguishable peak. A schematic of the test and an example plot of a test with a peak and one with no distinguishable peak are shown in Fig. 3. 


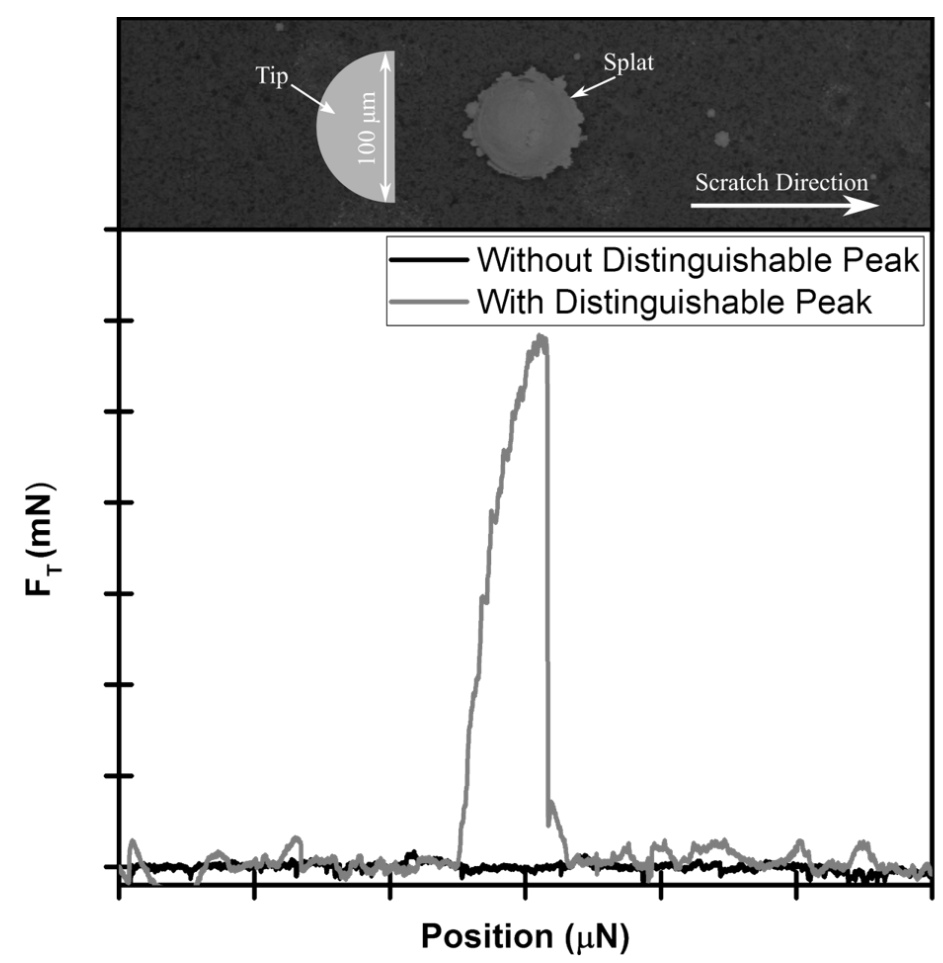

Fig. 3 Schematic of the splat adhesion test and output graph. The output graph shows a typical tangential force versus position graph with and without distinguishable peak

To process the splat adhesion test data, the baseline tangential force is subtracted from the peak. The baseline was subtracted in OriginLab using the $2^{\text {nd }}$ derivative method and fit with a spline. Adhesion strength is then measured by Eq 1 (Ref 27, 28). 


$$
\text { Adhesion Strength }[\mathrm{MPa}]=\frac{F_{T \text { Peak }}[\mathrm{mN}]-F_{T \text { Baseline }}[\mathrm{mN}]}{\text { Projected Splat Area }\left[\mu \mathrm{m}^{2}\right]} * 1000
$$

where the projected splat area can be measured by Eq 2 .

$$
\text { Projected Splat Area }\left[\mu m^{2}\right]=\pi\left(\frac{w[\mu m]}{2}\right)^{2}
$$

where $\mathrm{w}$ is the splat diameter measured using the light optical microscope (LOM) on the scratch tester prior to testing.

To determine the approximate equivalent powder diameter prior to deposition, Eq 3 is used (Ref 28, 30). FR is the flattening ratio which can be calculated by dividing the diameter of the splat by its height (Ref 28). The height of the splat is measured by subtracting the height of the microscope when focusing on the substrate from the height of the microscope when focusing on the top of the splat (Ref 27, 28).

$$
d[\mu m]=\left(\frac{w^{3}}{F R}\right)^{\frac{1}{3}}
$$

At least 35 splats were tested for each material combination studied over a wide range of powder sizes. To compare the effect of surface roughness and composition on adhesion strength, measurements are averaged for powder with an equivalent powder diameter between 20 and $40 \mu \mathrm{m}$ given an average powder size of $29 \mu \mathrm{m}$.

LOM images of failed interfaces were used to investigate the percentage of Ti remaining on the substrate with respect to the projected area of the splat. The area of the remaining $\mathrm{Ti}$ on the substrate was measured using color thresholding in ImageJ. The failed interfaces following splat adhesion testing were also analysed using the variable pressure mode of the SEM (SU-3500, 
Hitachi, Tokyo, Japan) at an accelerating voltage of $5 \mathrm{kV}$ and a $40 \mathrm{~Pa}$ air pressure to reduce charging effects from the bulk ceramic substrate. Metal/ceramic interfaces were cross-sectioned by mechanical grinding and polishing with $0.05 \mu \mathrm{m}$ colloidal silica mixed with $30 \%$ hydrogen peroxide. Polished interfaces were sputter-coated with chromium to reduce charging effects in the high pressure SEMs (SU-8000, Hitachi, Tokyo). The low accelerating voltage of $5 \mathrm{kV}$ was maintained.

\section{Results}

\subsection{Characterization of Ceramic Substrates}

Through EDS analysis, traces of elemental contaminants were found at the surface of both substrates. For $\mathrm{Al}_{2} \mathrm{O}_{3}$, the contaminants were mainly found between grains (Fig. 2 (a)). The main elements detected were calcium and magnesium with traces of chlorine, sodium and sulfur. These surface contaminants do not seem to influence the results, as backscattered electron (BSE) splat/substrate cross-sectional images do not show changes in contrast near the interface. Therefore, no contaminants are found in the interfaces. Figure 2 (b) shows grains with a dark contrast distributed throughout the surface of the SiC. EDS results showed that these darker grains contained boron. Furthermore, areas with a higher concentration of carbon were observed. Free carbon and boron are used as sintering aids for $\mathrm{SiC}$ to improve densification (Ref 31$)$.

The average $R_{p k}$ values of each sample are shown in Fig. 4 (a) for two magnifications. For all samples, the standard deviation is larger when measured at a higher magnification. Positioning of grains and pores does not significantly influence roughness at lower magnifications. Higher magnification measurements on a $87 \times 87 \mu \mathrm{m}^{2}$ surface area are indicative of the local heterogeneity encountered by splats. High standard deviations in surface roughness measurements may be 
reflected in variability found in the splat adhesion tests. Single splats encounter various substrate morphologies. Figure 4 (b)-(e) show representative surface topographies of each substrate on a $87 \mathrm{x} 87 \mu \mathrm{m}^{2}$ surface area. The as-received substrates are characterised by a series of fine peaks and valleys due to the morphology of the sintered grains. Polished substrates show minimal fine peaks with valleys caused by porosity.

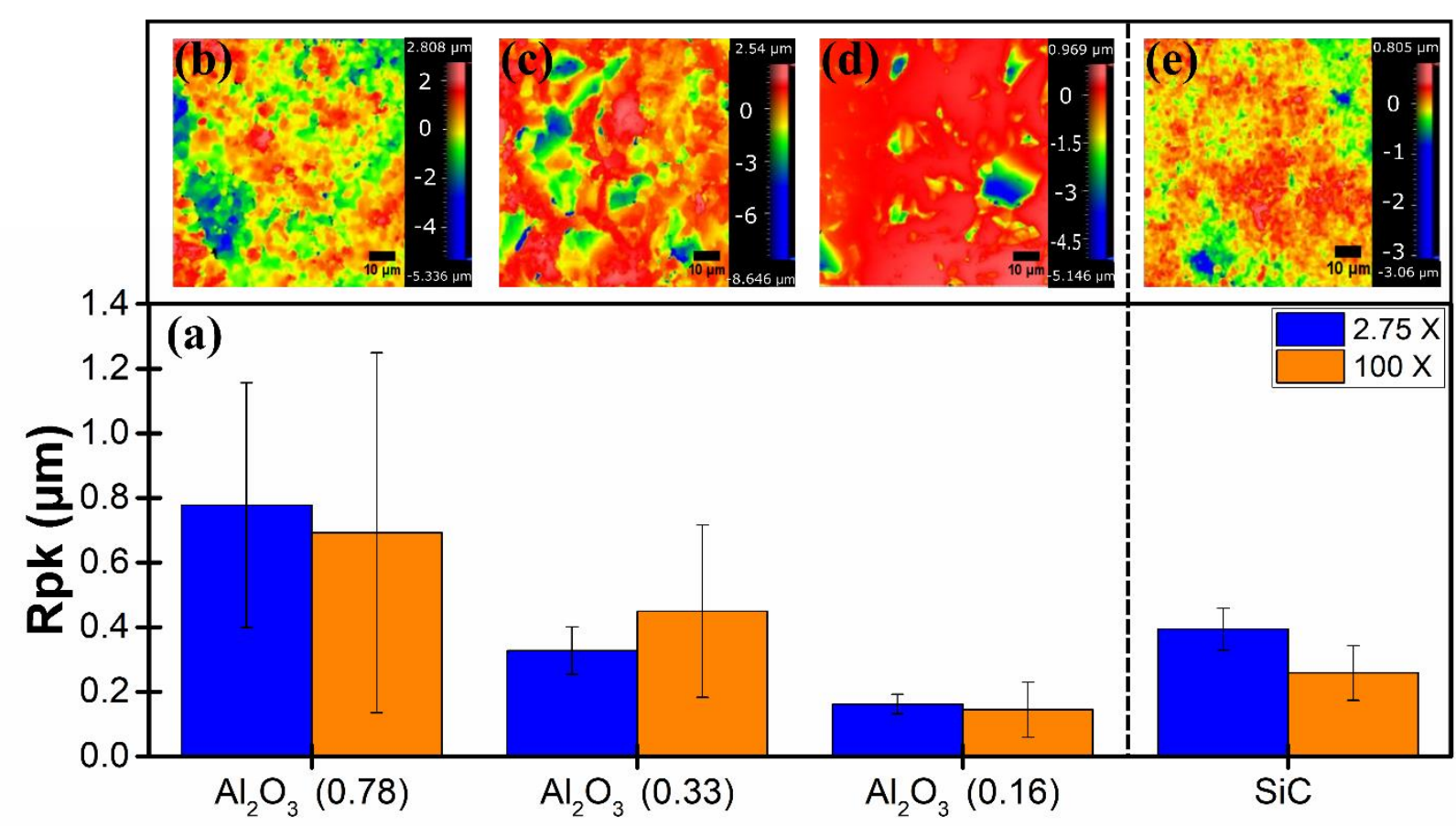

Fig. 4 (a) Surface roughness of $\mathrm{Al}_{2} \mathrm{O}_{3}$ and $\mathrm{SiC}$ substrates in addition to the surface morphology of (b) $\mathrm{Al}_{2} \mathrm{O}_{3}(0.78)$, (c) $\mathrm{Al}_{2} \mathrm{O}_{3}(0.33)$ and (d) $\mathrm{Al}_{2} \mathrm{O}_{3}(0.16)$ and (e) $\mathrm{SiC}$

\subsection{Splat Adhesion Testing}

\subsubsection{Adhesion Strength}

Splats with an equivalent powder diameter between $10 \mu \mathrm{m}$ and $40 \mathrm{um}$ were tested by splat adhesion testing (Fig. 5). For the $\mathrm{Al}_{2} \mathrm{O}_{3}$ substrates there is a decrease in bond strength with increase in powder diameter (Fig. 5). Similar trends were observed for splat adhesion testing of Ti splats 
deposited on Ti substrates (Ref 28). Finer powder particles have higher impact velocities than larger powder particles. The higher impact velocities cause higher adhesion strengths (Ref 28, 32, 33). For the $\mathrm{SiC}$ substrate, there are 18 splats that resulted in no distinguishable peak. The adhesion strength for these cases was assumed to be zero. From Fig. 5 (d) null results for the Ti/SiC interface were seen throughout the size distribution. No particular trend or relationship between powder size and probability of a null result was observed for the $\mathrm{Ti} / \mathrm{SiC}$ interface. For measurable adhesion strengths in the $\mathrm{Ti} / \mathrm{SiC}$ interface, average adhesion strength appears to be slightly higher than for finer powder particles in the range of 10 to $20 \mu \mathrm{m}$. However, there was no trend of adhesion strength with powder diameter for the $\mathrm{Ti} / \mathrm{SiC}$ interfaces, which was different from the $\mathrm{Ti} / \mathrm{Al}_{2} \mathrm{O}_{3}$ interfaces.

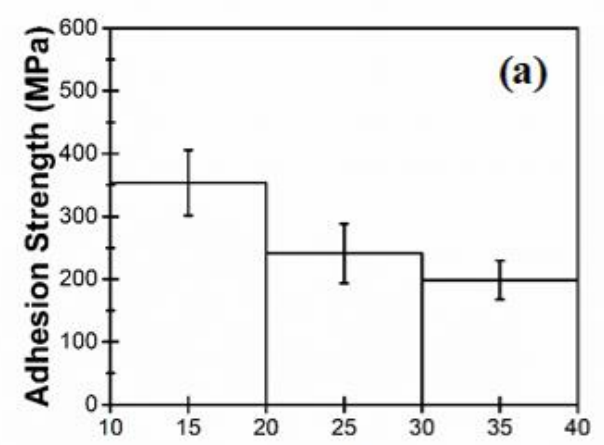

Equivalent Powder Diameter $(\mu \mathrm{m})$

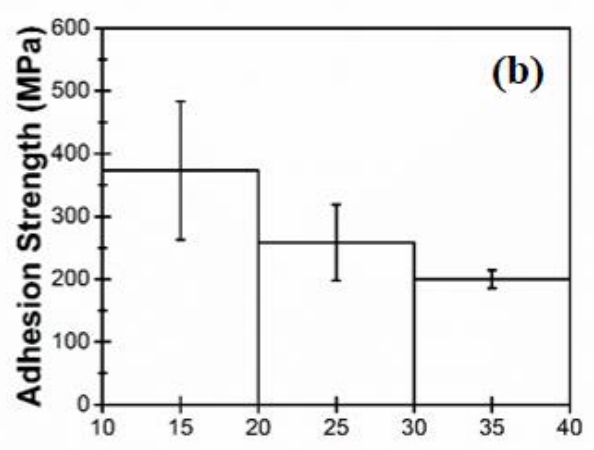

Equivalent Powder Diameter $(\mu \mathrm{m})$

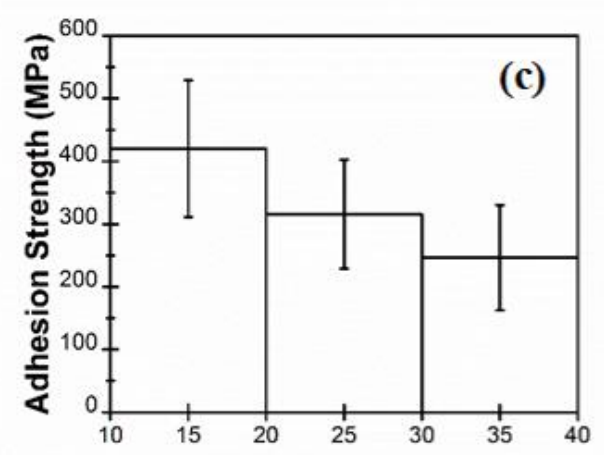

Equivalent Powder Diameter $(\mu \mathrm{m})$

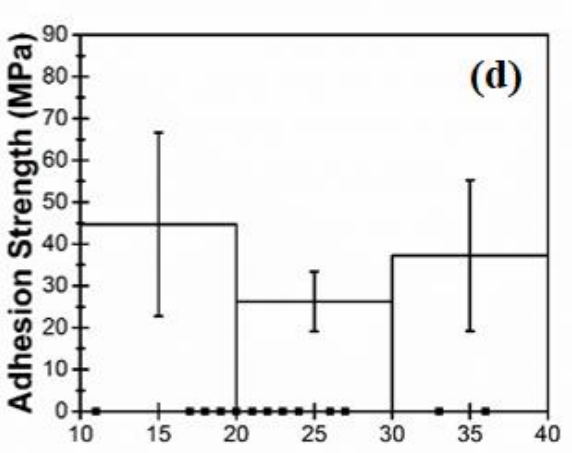

Equivalent Powder Diameter $(\mu \mathrm{m})$

Fig. 5 Effect of equivalent powder diameter on adhesion strength between $\mathrm{Ti}$ and (a) $\mathrm{Al}_{2} \mathrm{O}_{3}(0.78$ ), (b) $\mathrm{Al}_{2} \mathrm{O}_{3}$ (0.33), (c) $\mathrm{Al}_{2} \mathrm{O}_{3}(0.16)$ and (d) $\mathrm{SiC}$. (d) includes null results for the $\mathrm{Ti} / \mathrm{SiC}$ interface as points along the $\mathrm{x}$-axis 
Given the average powder size of $29 \mu \mathrm{m}$ and the powder size distribution, averages are compared for an equivalent powder diameter between 20 and $40 \mu \mathrm{m}$ (Fig. 6). Splat adhesion test results showed significantly higher adhesion between all $\mathrm{Ti}$ and $\mathrm{Al}_{2} \mathrm{O}_{3}$ substrates than between $\mathrm{Ti}$ and $\mathrm{SiC}$ substrates. 13 of the 26 tests conducted for the Ti/SiC interface, in this size range, resulted in a null adhesion strength. These results were not included to measure the average adhesion strength.

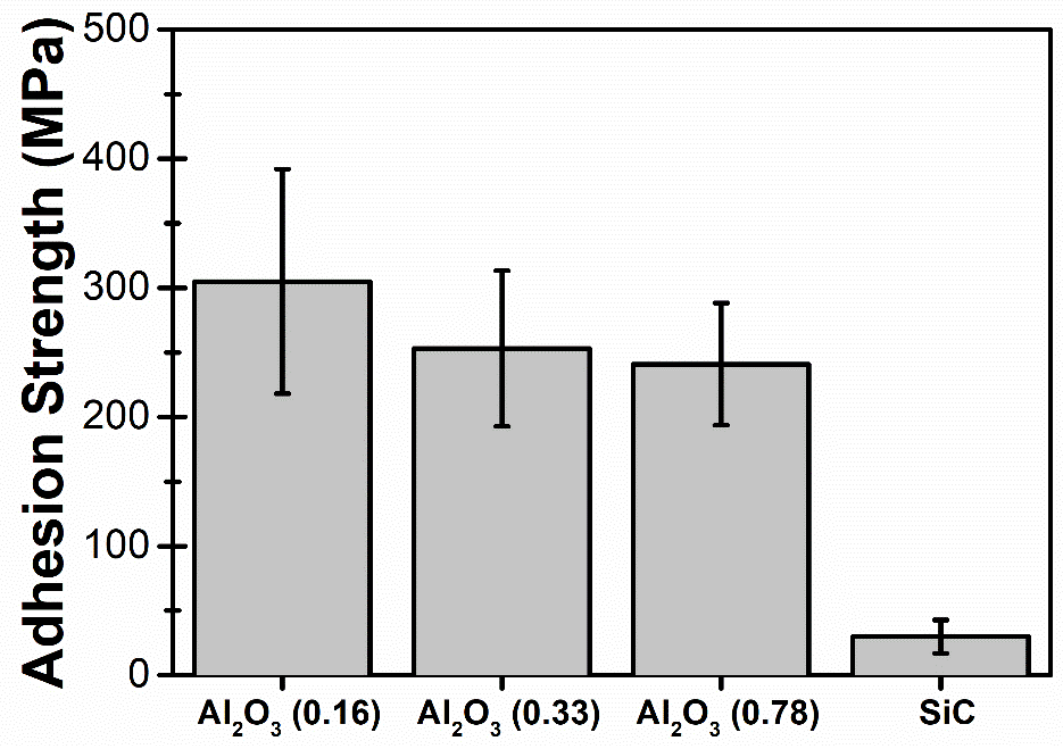

Fig. 6 Average adhesion strength by splat adhesion testing for powder diameters varying from 20 $\mu \mathrm{m}$ to $40 \mu \mathrm{m}$ deposited on all substrates with the standard deviation as the error bar 
$\mathrm{Al}_{2} \mathrm{O}_{3}(0.16)$ had the highest bond strength. A Student T-test* was used to validate if the bond strength measurements are significantly different with decreasing surface roughness. The difference between $\mathrm{Al}_{2} \mathrm{O}_{3}(0.33)$ and $\mathrm{Al}_{2} \mathrm{O}_{3}$ (0.78) was not significant. The difference between $\mathrm{Al}_{2} \mathrm{O}_{3}(0.16)$ and the two other substrates was significant.

\subsubsection{Splat Morphology}

Figure 7 shows the top view of a single splat deposited on $\mathrm{Al}_{2} \mathrm{O}_{3}(0.78), \mathrm{Al}_{2} \mathrm{O}_{3}(0.16)$ and $\mathrm{SiC}$. Splats typically show jetting along the edges of the powder due to ASI as commonly observed in cold spray (Ref 3, 5). Losses in kinetic energy required to adapt to the rougher substrate morphology do not cause reduced jetting in the $\mathrm{Ti} / \mathrm{Al}_{2} \mathrm{O}_{3}$ interface (Fig. 7 (a)). Also, differences in adhesion strength cannot be identified through splat morphology. Single Ti splats deposited on $\mathrm{SiC}$ also show a similar morphology to those deposited on $\mathrm{Al}_{2} \mathrm{O}_{3}$, despite their significantly lower adhesion strength (Fig. 7 (c)).

\footnotetext{
* A two-tailed T-test was used given that the number of tests and the variance for each test conditions was not equal. The null hypothesis, that is the hypothesis that there is no difference between the means, was rejected if the P-value was smaller than 0.05 . Therefore, a statement can be made that, despite the standard deviation in the data, the means are statistically different with at least a $95 \%$ level of confidence when the null hypothesis is rejected.
} 

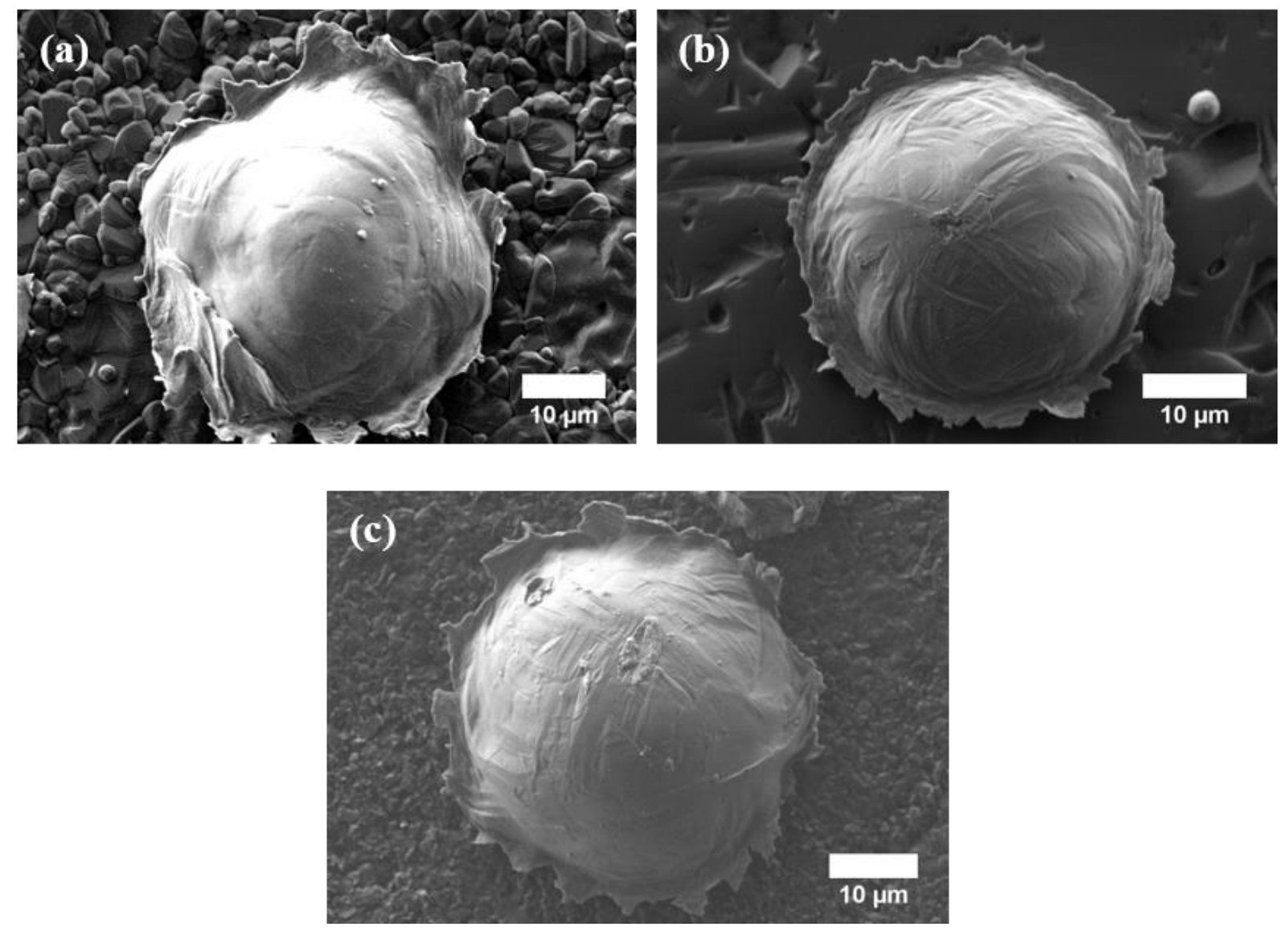

Fig. 7 Single Ti splat deposited on (a) $\mathrm{Al}_{2} \mathrm{O}_{3}$ (0.78), (b) $\mathrm{Al}_{2} \mathrm{O}_{3}$ (0.16) and (c) $\mathrm{SiC}$ showing formation of ASI

Cross-sectional images of single Ti splats deposited on $\mathrm{Al}_{2} \mathrm{O}_{3}$ (0.78) (Fig. 8) and $\mathrm{SiC}$ (Fig. 9) showed significant differences despite no observable differences in the plan view splat morphology. Cross-sectional imaging of the $\mathrm{Ti}$ splats deposited on $\mathrm{Al}_{2} \mathrm{O}_{3}(0.78)$ showed a very continuous interface. The Ti was found to follow the morphology of the substrate even within pores. Figure 8 (a) shows the interface morphology and Fig. 8 (b) emphasized the grains of the Ti powder through ECC. The material which has penetrated within the pores has nano-sized grains showing evidence of extensive deformation. When the rougher ceramic surface is impacted, the fine peaks create a zone of higher pressure due to the reduced surface area at the location of initial 
impact giving localized plasticity within the impacting powder. When the Ti particle impacts on the rougher $\mathrm{Al}_{2} \mathrm{O}_{3}$ substrate, it is locally deformed around the peaks of the surface, allowing it to penetrate more easily into the pores in addition to the general adiabatic shearing of the particle (Ref 34).
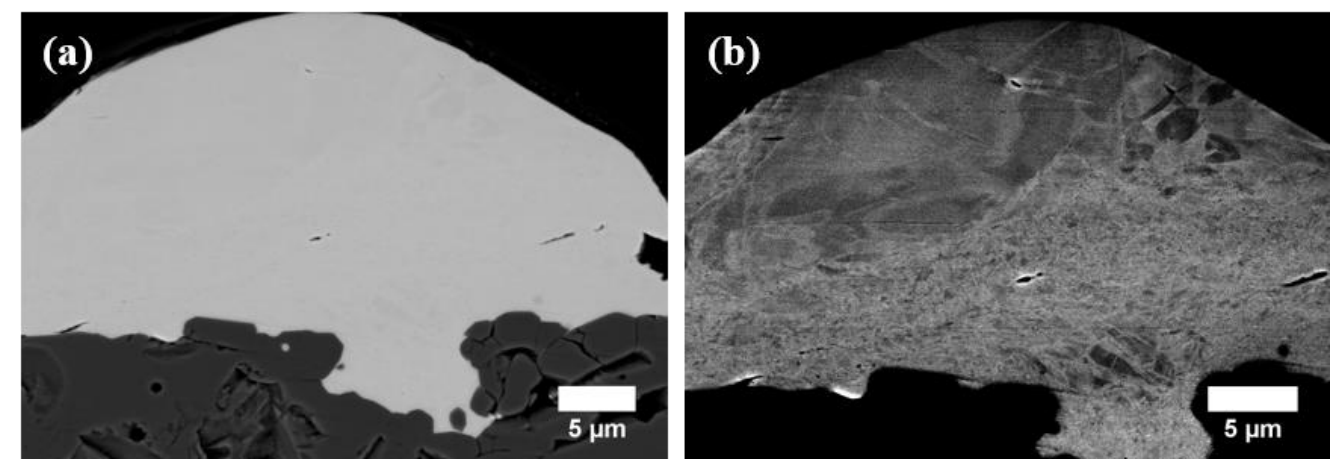

Fig. 8 Backscattered electron microscopy image of single splat cross-section deposited on $\mathrm{Al}_{2} \mathrm{O}_{3}$ (0.78) emphasizing (a) interface morphology and (b) grain in the Ti splat

Mechanical cross-sectioning of single splats on SiC (Fig. 9) mainly showed gapping between the splat and the substrate with minor mechanical clamping. The weakly bonded particles allowed the epoxy to penetrate the gap between the splat and the substrate (Fig. 9 (a)). The SiC beneath the splat, in some cases, is more porous than the bulk portion (Fig. 9 (b)). Microcracking from the impact occurs in this region. The higher hardness of the $\mathrm{SiC}$ makes it more brittle than the $\mathrm{Al}_{2} \mathrm{O}_{3}$. These microcracks cause material beneath the splat to fall during polishing making it appear more porous. 

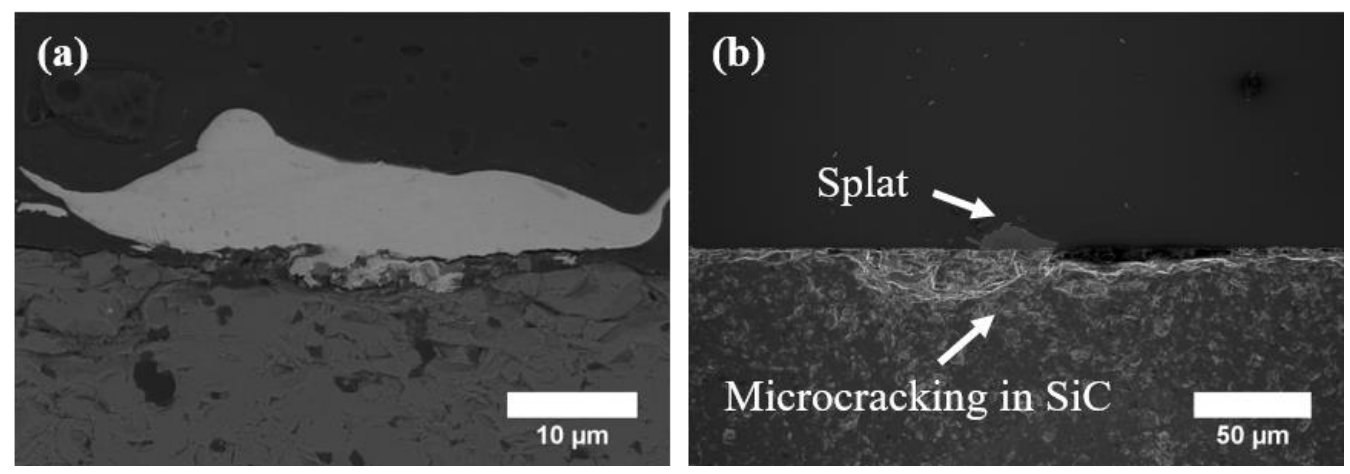

Fig. 9 Cross-section of $\mathrm{Ti} / \mathrm{SiC}$ interface showing poor bonding. (a) shows a high magnification image to identify interface feature while (b) shows a low magnification image to show cracking in the ceramic substrate

\subsubsection{Post-Test Characterization}

Failed interfaces from splat adhesion testing revealed traces of $\mathrm{Ti}$ on the substrates. The morphology and quantity of the $\mathrm{Ti}$ in the failed interface is indicative of the splat's bonding mechanism and strength. Color thresholding of LOM images of the failed interfaces was used to determine the relationship between the amount of $\mathrm{Ti}$ on the surface and adhesion strength.

For the $\mathrm{Ti} / \mathrm{Al}_{2} \mathrm{O}_{3}(0.16)$ interface, three cases were observable in post-test characterization. Case 1 is characterized by a circular ring of Ti remaining in the failed interface. The adhering ring of $\mathrm{Ti}$ does not significantly protrude from the surface of the substrate. Splats which left a ring on the surface of $\mathrm{Al}_{2} \mathrm{O}_{3}(0.16)$ impacted areas with minimal porosity. Figure 10 shows a representative image of a Case 1 failed interface. Figure 10 also shows the linear relation with a coefficient of determination $\left(\mathrm{R}^{2}\right)$ of 0.8 between the adhesion strength and the percentage of Ti remaining on the substrate for Case 1 .

The surface morphology at the splat level can vary significantly even on the polished substrate due to porosity. Pre-existing porosity in the ceramic substrate or potential induced fracture influenced the morphology of the failed interface. In the presence of large pores, the remaining Ti was found 
mainly in smooth areas. Figure 10 shows a representative image of a failed interface of this type, which is designated Case 2. Also, a linear relation between adhesion strength and the amount of Ti in the failed interface was found for Case 2 where fit showed an $\mathrm{R}^{2}$ value of 0.7. The adhesion strength is influenced by removal of Ti from the pore, potential removal of fractured ceramic and shearing of the Ti. For the same percentage of Ti on the substrate, the adhesion strength is higher for Case 2 than Case 1. In Case 1, the shearing of Ti mainly contributes to adhesion strength.

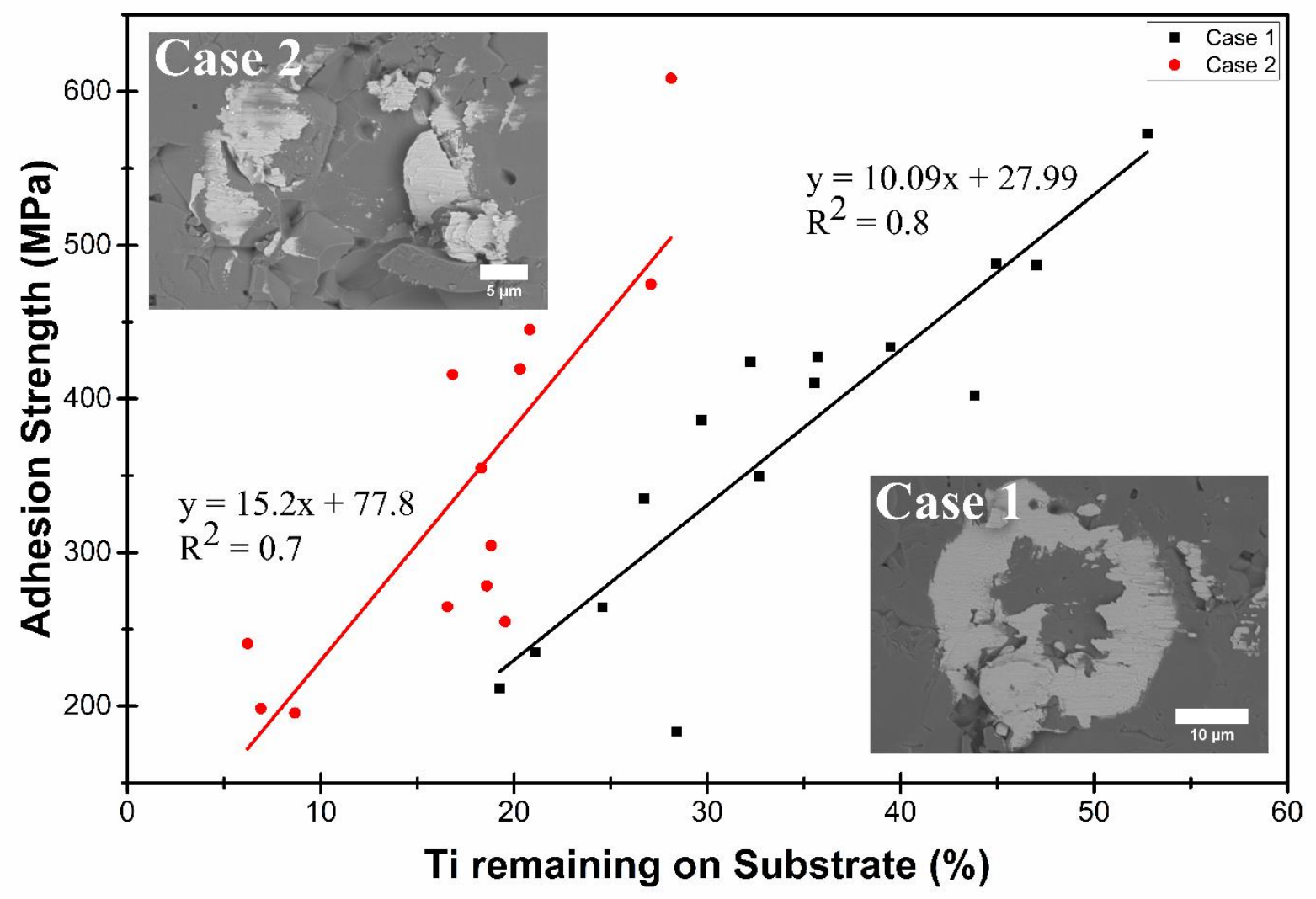

Fig. 10 Adhesion strength with respect to the percentage of Ti remaining on the substrate following splat adhesion testing with regards to the projected splat area for Cases 1 and 2 on $\mathrm{Al}_{2} \mathrm{O}_{3}$ (0.16). Representative images of Case 1 and Case 2 failed interfaces on $\mathrm{Al}_{2} \mathrm{O}_{3}(0.16)$ are also included 
Case 3 is characterized by a series of fine pores on the surface of $\mathrm{Al}_{2} \mathrm{O}_{3}(0.16)$. Fine, weakly bonded debris of Ti was found to remain on the substrate following splat adhesion testing (Fig. 11). Only a few tested particles resulted in a Case 3 failed interface. Splats had both high and low adhesion strengths in Case 3. No relationship could be established between percentage of Ti on the substrate and adhesion strength.

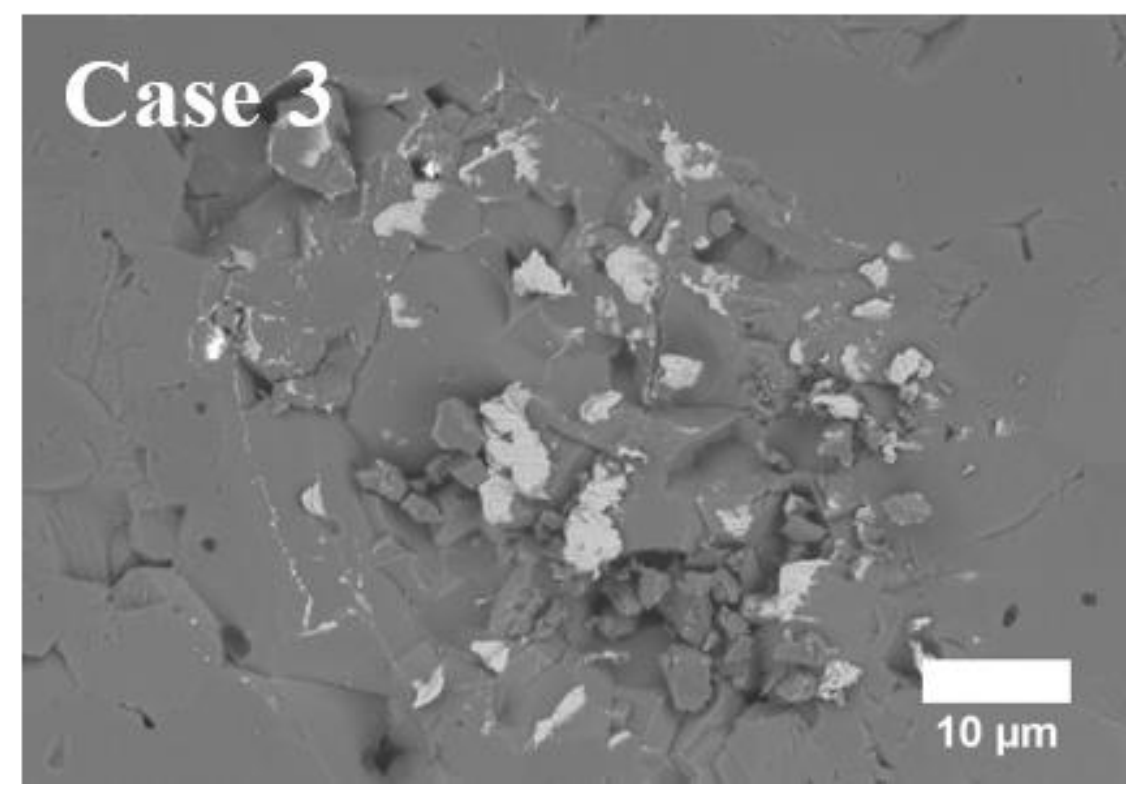

Fig. 11 Case 3 failed interface between Ti on Al2O3 (0.16) following splat adhesion testing The amount and characteristics of the remaining Ti on the surface of $\mathrm{Al}_{2} \mathrm{O}_{3}(0.33)$ and $\mathrm{Al}_{2} \mathrm{O}_{3}(0.78)$ were similar. Scattered parts of Ti remained on the substrates where the splat was removed, showing evidence of localized bonding. Representative images are shown in Fig. 12. Ti remaining on $\mathrm{Al}_{2} \mathrm{O}_{3}(0.78)$ is mainly within the pores and rarely along the surface of the substrate. These failed interfaces differ from those in Case 3 on $\mathrm{Al}_{2} \mathrm{O}_{3}(0.16)$ as the Ti remaining on the surface appears well bonded and continuous with the grains of the substrate. From the post-test 
characterization, it can be concluded that adhesion strength between single splats of $\mathrm{Ti}$ on $\mathrm{Al}_{2} \mathrm{O}_{3}$ $(0.78)$ is mainly due to mechanical clamping.

The amount of Ti remaining on the substrate varies significantly from one splat to the other. The adhesion strength with respect to the percentage of the Ti remaining on the $\mathrm{Al}_{2} \mathrm{O}_{3}(0.78)$ substrate was also plotted in Fig. 12. It was found that a linear trend with high variance $\left(\mathrm{R}^{2}=0.45\right)$ exists between adhesion strength and quantity of Ti remaining on the substrate. Similarly to Case 2 on the $\mathrm{Al}_{2} \mathrm{O}_{3}(0.16)$ substrate, the high variance can be attributed to effects contributing to adhesion strength measurements such as the extraction of Ti from within pores or detachment of ceramic grains. The adhesion strength for low percentages of $\mathrm{Ti}$ on the substrate is higher than what was observed for the $\mathrm{Al}_{2} \mathrm{O}_{3}(0.16)$ substrate. However, the splats deposited on $\mathrm{Al}_{2} \mathrm{O}_{3}(0.16)$ tend to have a higher percentage of $\mathrm{Ti}$ remaining on the substrate, following the test, contributing to its overall higher average adhesion. 


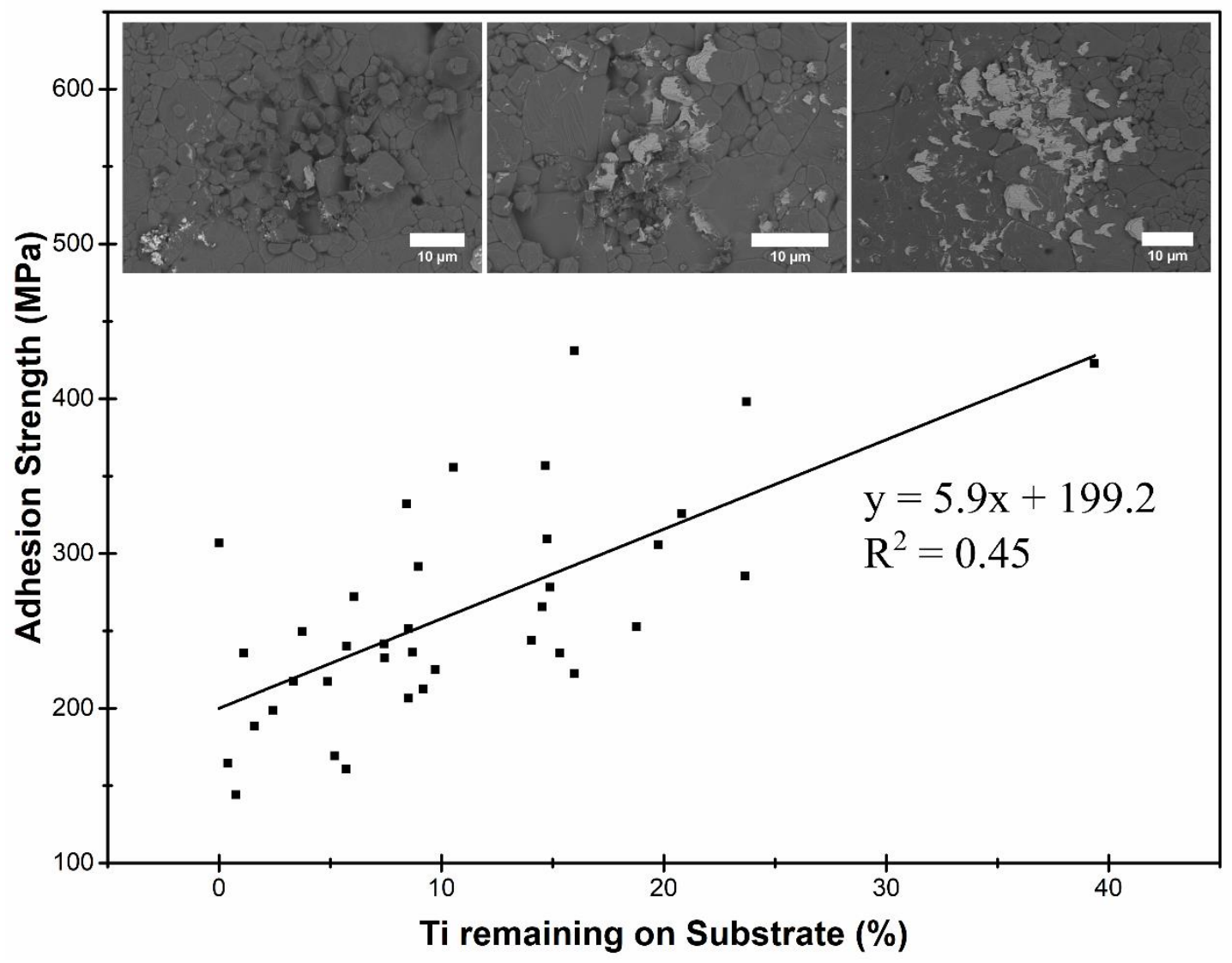

Fig. 12 Adhesion strength with respect to the amount of Ti that remains on the substrate following splat adhesion testing for the $\mathrm{Al}_{2} \mathrm{O}_{3}(0.78)$ substrate

The bonding mechanism of $\mathrm{Ti}$ particles sprayed on smooth and rough $\mathrm{Al}_{2} \mathrm{O}_{3}$ substrates is significantly different. Mechanical clamping appears to play a more significant role in bonding with the rougher surfaces, but mechanical clamping is not necessarily the only bonding mechanism for cold spraying metal powder on ceramic substrates given the results obtained on the smoother substrates. Bonding also occurs in the zone of ASI, where the temperature is at the highest and deformation is most significant (Ref 3, 35). Hence, ASI is likely a necessary occurrence for bonding on the smooth ceramic substrates. 
For the Ti splats deposited on $\mathrm{SiC}$, following splat adhesion testing, there is mainly no evidence of bonding with no Ti remaining on the substrate. Fracture of the substrate is sometimes observable or, in very few cases, a small portion of Ti remained on the substrate (Fig. 13).
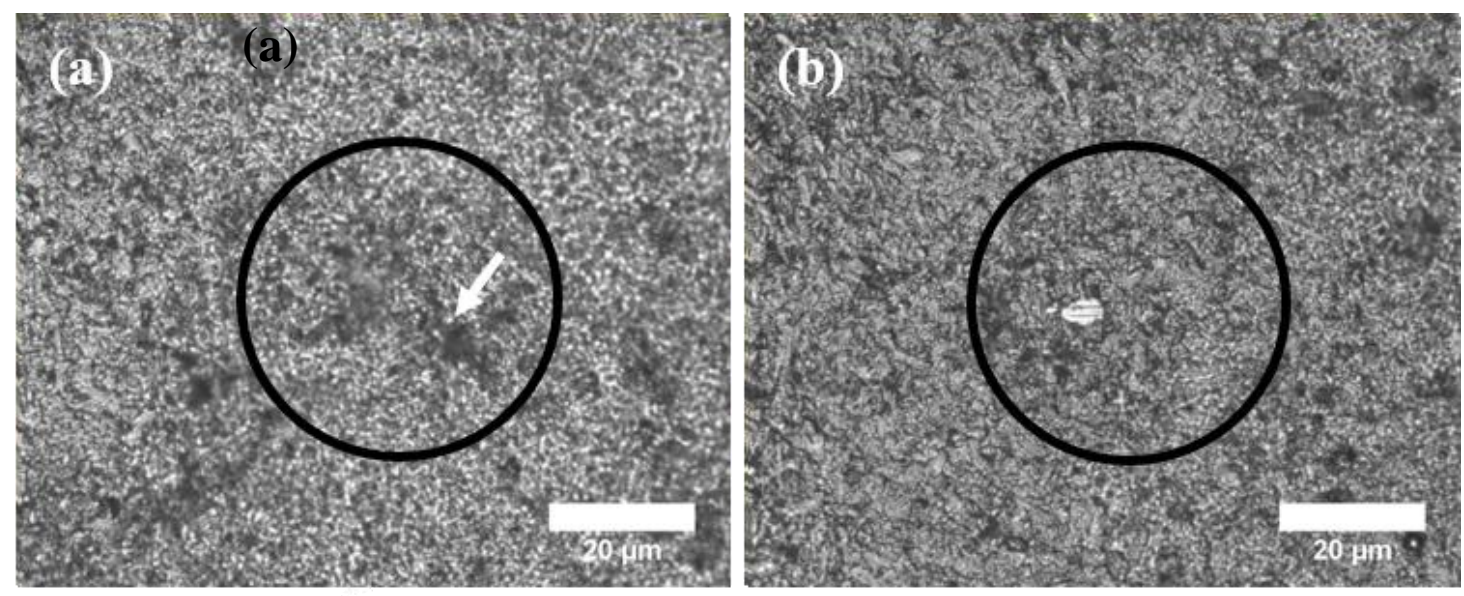

Fig. 13 Representative LOM image of failed interface on $\mathrm{SiC}$ (a) shows a remaining interface with no evidence of $\mathrm{Ti}$ and some minor fracturing of the ceramic identified by an arrow, and (b) shows minor evidence of $\mathrm{Ti}$ remaining on the $\mathrm{SiC}$

BSE images revealed traces of Ti on the surface of the substrate from rebounded or weakly bonded particles which fell off of the substrate. A splat that was removed by splat adhesion testing could not be distinguished from a rebounded splat. These fine traces of Ti were not identifiable by LOM. The traces of Ti remaining on the substrate due to rebounded or detached splats are in the shape of a ring (Fig. 14). Within the ring, the fine traces of Ti appear along the surface and not solely within cracks. This demonstrates that extremely localized bonds are formed within the same area that a complete bond is formed between some Ti splats and $\mathrm{Al}_{2} \mathrm{O}_{3}(0.16)$ substrate. An example is marked by an arrow in Fig. 14. Bonding between $\mathrm{Ti}$ and $\mathrm{SiC}$ is extremely localized in comparison to $\mathrm{Al}_{2} \mathrm{O}_{3}$. 

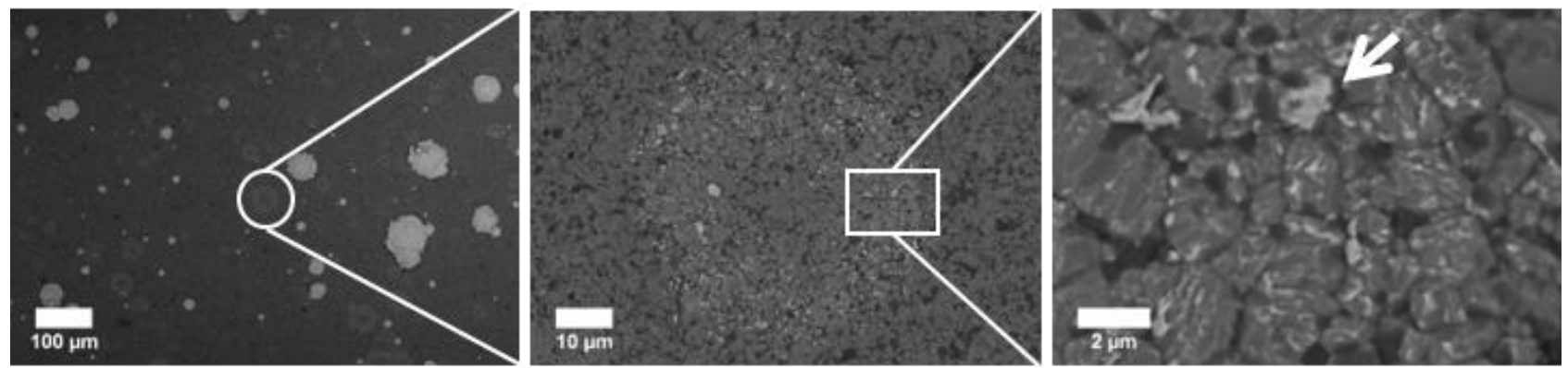

Fig. 14 Circular ring with traces of $\mathrm{Ti}$ appearing on $\mathrm{SiC}$ in locations where the particle has rebounded or fallen

\section{Discussion}

\subsection{Adhesion strength}

Direct comparisons of splat adhesion test to a bulk coating adhesion test are somewhat difficult due to the different length scales and different loading conditions. Splat adhesion test data provides adhesion at the single splat level while typical tensile testing techniques are intended to characterize full coatings. Goldbaum et al. (Ref 28) showed however that splat adhesion tests correlated well to a bulk coating cohesion measurement for cold sprayed Ti. For the $\mathrm{Ti}_{1} / \mathrm{Al}_{2} \mathrm{O}_{3}$ and $\mathrm{Ti} / \mathrm{SiC}$ systems, this work represents the first application of the splat adhesion test. Also, even for bulk tests, there have been no reported bond strength measurements for the $\mathrm{Ti} / \mathrm{Al}_{2} \mathrm{O}_{3}$ and $\mathrm{Ti} / \mathrm{SiC}$ interface in previous literature. However, some qualitative comparisons can be made using other material systems. Few metal coatings deposited on ceramic substrates by cold spray have been tested by bulk coating adhesion tests. Al has been the most prominent metal investigated in metal/ceramic adhesion by cold spray. Adhesion of $\mathrm{Al}$ coatings to $\mathrm{MgF}_{2}, \mathrm{Al}_{2} \mathrm{O}_{3}, \mathrm{Si}_{3} \mathrm{~N}_{4}, \mathrm{SiC}$ and $\mathrm{AlN}$ substrates maintained at room temperature are all significantly lower than values obtained here in the $\mathrm{Ti} / \mathrm{Al}_{2} \mathrm{O}_{3}$ interface (Ref $18,19,21,22$ ). Higher adhesion strengths are obtained with an increase in substrate temperature and through heat treatment (Ref 18, 22). Values remain lower than 
adhesion between $\mathrm{Ti}$ and $\mathrm{Al}_{2} \mathrm{O}_{3}$. Bulk coating adhesion tests of $\mathrm{Al} / \mathrm{SiC}$ interfaces are comparable to values obtained by splat adhesion testing in the $\mathrm{Ti} / \mathrm{SiC}$ interface.

The bond strength of Ti deposited on $\mathrm{Al}_{2} \mathrm{O}_{3}$ is comparable or, in some cases, higher than the values reported by Goldbaum et al. for Ti deposited on $\mathrm{Ti}(\operatorname{Ref} 28)$. The sheared Ti remaining in the failed interface has been highly deformed at impact, and therefore has a higher shear strength than bulk Ti. The $\mathrm{Al}_{2} \mathrm{O}_{3}$ substrate has a higher hardness than a Ti substrate. Thus, the impact onto $\mathrm{Al}_{2} \mathrm{O}_{3}$ induces more deformation in the splat than the Ti substrate at impact. This phenomenon can explain the higher adhesion strength measured in certain cases in the $\mathrm{Ti} / \mathrm{Al}_{2} \mathrm{O}_{3}$ interface. Removal of fractured ceramic grains or surface roughness can also influence adhesion in the $\mathrm{Ti} / \mathrm{Al}_{2} \mathrm{O}_{3}$ interface.

For metal/metal splat adhesion testing, where the two metals are of the same material, it is impossible to determine the fraction of metal from the splat remaining on the substrate. However, in the work of Goldbaum et al., they observed that, for their highest adhesion strengths, the test was shearing through the splat very close to the bonded interface (Ref 28). This indicates a very good metallurgical bond and the splat adhesion test at this point measures mechanical properties of the splat itself. From post-test characterization of $\mathrm{Ti}_{1} / \mathrm{Al}_{2} \mathrm{O}_{3}$ interfaces, the amount of $\mathrm{Ti}$ remaining on the substrate was measured and correlated to the bond strength. Also, the morphology of the remaining Ti provided information with regards to the bonding mechanism. As the tip applies a tangential pressure on the splat, an interface crack spreads leading to the eventual detachment of the splat. The crack spreads through the weakest part of the interface. In the case where crack spreading leaves Ti on the surface of the substrate, it is indicative of a strong bond between the splat and the substrate. The adhesion at the interface is stronger than the cohesion of the splat itself. This was observed when $\mathrm{Ti}$ was deposited on $\mathrm{Al}_{2} \mathrm{O}_{3}$ (0.16). When deposited on 
$\mathrm{Al}_{2} \mathrm{O}_{3}$ (0.78), the Ti remained within pores rather than on the surface. The interface was therefore composed of both $\mathrm{Al}_{2} \mathrm{O}_{3}$ and $\mathrm{Ti}$. When mechanical bonding is the predominant bonding mechanism, shearing of Ti is necessary to remove the splat. Splat adhesion testing in the rough interface therefore provides a measure of how well the particle is mechanically bonded.

\subsection{Adhesion Rings}

Adhesion between single splats of $\mathrm{Ti}$ and smooth substrates was not solely dependent on mechanical clamping. Following splat adhesion testing, a ring of Ti remained on $\mathrm{Al}_{2} \mathrm{O}_{3}(0.16)$ in locations where minimal porosity was observed. Similarly, fine traces of Ti were found in a ring shape when deposited on $\mathrm{SiC}$ for rebounded or fallen splats. Various models $(\operatorname{Ref} 3,5,35)$ and experimental works (Ref 28, 36) have shown the link between ASI and adhesion in metallic systems. In splat adhesion testing, a similar ring was previously observed for $\mathrm{Ti} / \mathrm{Ti}$ and Ti6A14V/Ti6A14V interfaces as reported by Goldbaum et al. (Ref 28). While the center of the powder is exposed to the highest hydrostatic pressure, adhesion does not occur. Rather, shear forces within the adiabatically sheared jet are associated with bonding (Ref $8,23,36,37)$. The presence of a ring of $\mathrm{Ti}$ on $\mathrm{Al}_{2} \mathrm{O}_{3}(0.16)$ and on $\mathrm{SiC}$ shows that ASI are significant to bonding in metal/ceramic systems with low surface roughness. Adhesion in the periphery of single splats of Ti deposited onto $\mathrm{ZrO}_{2}$ due to ASI has also previously been shown (Ref 23). Similarly, adhesion rings were observed for $\mathrm{Cu} / \mathrm{Al}_{2} \mathrm{O}_{3}$ interfaces (Ref 11).

Drehmann et al. (Ref 18, 19), as well as Wüstefeld et al. (Ref 13) and Rafaja et al. (Ref 17) also suggested that mechanical clamping is not the sole contributing factor to adhesion in metal/ceramic interfaces created by cold spray. Hetero-epitaxy between the metal and ceramic lattices contributes to bonding due to the energy stored in microstructural defects caused during plastic deformation 
in the metal and heating in the interface (Ref $13,17,18,19)$. Rafaja et al. extended the concept of hetero-epitaxy to polycrystalline $\mathrm{Al}_{2} \mathrm{O}_{3}$ interfacing $\mathrm{Ti}$, as these materials show a small lattice misfit along multiple planes (Ref 17). On the other hand, Ko et al. attributed adhesion in metal/ceramic systems to atomic intermixing as a result of amorphisation due to extreme plastic deformation (Ref 20). Also, Kim et al. suggested that bonding is attributable to the intimate contact between the metal and the ceramic as surface oxides are removed due to ASI (Ref 23). Surface activated bonding is based on the premise that two clean surfaces in intimate contact will form a bond. Clean metal surfaces have a natural tendency to react with oxygen, nitrogen or carbon (Ref 38, 39). Metals and oxides have been shown to bond by this technique in their solid-state (Ref 23, 39). Here, it was shown that adhesion occurs due to ASI in smooth interfaces. ASI are associated to the location of highest temperature. The previously discussed bonding mechanisms such as heteroepitaxy, surface activated bonding or atomic intermixing due to amorphisation require atomic motion at the interface. It is therefore consistent that ASI lead to the formation of any of these chemico-physical interactions. 


\subsection{Effect of surface roughness}

From post-test characterization of single splats deposited on $\mathrm{Al}_{2} \mathrm{O}_{3}$ with different surface roughness, mechanical clamping is observed when peaks and valleys are present. On the rougher substrate, Ti remained between the grains of $\mathrm{Al}_{2} \mathrm{O}_{3}$ but for splats on smoother surfaces, a ring morphology was observed showing evidence of a potential chemical interaction. There are only few studies addressing surface roughness in metal/ceramic interfaces created by cold spray. Images of $\mathrm{Al}$ splats deposited on $\mathrm{Al}_{2} \mathrm{O}_{3}$ revealed that mechanical bonding assisted in bond formation on rougher substrate or though porosity on smoother substrates (Ref 19). However, a Ti coating on a smooth sapphire substrate was well-bonded while deposition onto a rougher sapphire substrate resulted in delamination ( $\operatorname{Ref} 17)$.

Some insight can also be obtained from the literature on metal/metal interfaces. Hussain et al. observed that high surface roughness prevented metallurgical bonding in an $\mathrm{Al} / \mathrm{Cu}$ interface. Mechanical bonding was the main bonding mechanism (Ref 40). Kumar et al. also found that when depositing a soft metal on a hard metal (Al on mild steel), surface roughness influenced adhesion. The bond strength increased with surface roughness until a certain point. For very rough substrates, adhesion decreased. Mixed adhesion mechanisms (metallurgical bonding and mechanical bonding) allowed for high adhesion strength in intermediate surface roughness values (Ref 41). Similarly in this work, roughness highly influenced the adhesion mechanism in the $\mathrm{Ti} / \mathrm{Al}_{2} \mathrm{O}_{3}$ interface. A transition from mechanical bonding to chemical bonding was observable with decreased surface roughness. 


\subsection{Effect of substrate composition}

Drehmann et al. (Ref 18) investigated the effect of the percentage of ionic and covalent bonding in the ceramic on adhesion between the $\mathrm{Al}$ and various ceramics in cold spray, as more covalently bonded ceramics tend to be easily wetted by metals. However, higher ionicity of the ceramic did not correlate to higher adhesion strength. Furthermore, poor bonding was not adequately explained by differences in coefficients of thermal expansion mismatch between the metal and the ceramic. Instead, they proposed that a ceramic's higher thermal conductivity can assist in the formation of a hetero-epitaxial bond (Ref 18). For the Ti splats interfacing with $\mathrm{Al}_{2} \mathrm{O}_{3}$ and $\mathrm{SiC}$, a stronger bond was formed with the more ionic ceramic further emphasizing that the bond between the cold sprayed metal and the ceramic does not follow the same trend as wetting behaviours between them. From the manufacturer data sheet, $\mathrm{Al}_{2} \mathrm{O}_{3}$ has a thermal conductivity of $30 \mathrm{~W} / \mathrm{mK}$ and $\mathrm{SiC}$ $150 \mathrm{~W} / \mathrm{mK}$. The higher thermal conductivity of the SiC did not assist in the formation of a bond. Ti splats deposited on SiC appear to form highly localized, weak bonds. Gaps were found through most of the interface of the deposited single splats. Drehmann et al. also observed significant gapping between a full coating of $\mathrm{Al}$ on $\mathrm{SiC}$ and single $\mathrm{Al}$ splats on $\mathrm{Al}_{2} \mathrm{O}_{3}$ substrate $(\mathrm{Ref} 18,19)$. This is considerably different to what was observed when depositing single Ti splats on $\mathrm{Al}_{2} \mathrm{O}_{3}$. The $\mathrm{Ti} / \mathrm{Al}_{2} \mathrm{O}_{3}$ interface appeared continuous and rendered very strong bonds under identical spray conditions to the depostion of Ti on SiC. Cracking of $\mathrm{SiC}$ was observed for Ti/SiC interfaces. This shows that the impact fracture toughness of the ceramic influences adhesion in cold sprayed metal/ceramic interfaces. 


\section{Conclusion}

A better understanding of metal/ceramic interfaces is necessary to optimize metal matrix composites and ceramic metallization created by cold spray. Splat adhesion testing provided insight into bond formation between Ti splats deposited on $\mathrm{Al}_{2} \mathrm{O}_{3}$ and $\mathrm{SiC}$. The adhesion strength of $\mathrm{Ti}$ deposited on $\mathrm{Al}_{2} \mathrm{O}_{3}$ is shown to be significantly higher than $\mathrm{SiC}$. The type of ceramic has an important influence on adhesion. The Ti/SiC interface showed micro-cracking of the ceramic and gapping while the $\mathrm{Ti} / \mathrm{Al}_{2} \mathrm{O}_{3}$ interface appeared continuous.

The as-received ceramic substrates had significantly different roughness. $\mathrm{Al}_{2} \mathrm{O}_{3}$ was therefore polished to three final roughnesses of $R_{\mathrm{pk}}=0.78,0.33$ and $0.16 \mu \mathrm{m}$ to investigate the effect of surface roughness on adhesion strength. The bonding mechanism between $\mathrm{Al}_{2} \mathrm{O}_{3}(0.78)$ and $\mathrm{Al}_{2} \mathrm{O}_{3}$ (0.16) was significantly different. Splats deposited on $\mathrm{Al}_{2} \mathrm{O}_{3}(0.78)$ bonded mechanically with $\mathrm{Ti}$ infiltration into surface pores. Splats deposited on non-porous sections of $\mathrm{Al}_{2} \mathrm{O}_{3}(0.16)$ formed adhesion rings due to ASI. Where large pores on $\mathrm{Al}_{2} \mathrm{O}_{3}(0.16)$ were present, Ti remained on the substrate in the comparatively smooth areas. Some splats landed in areas with fine pores and left minimal Ti on the surface. For the same amount of Ti remaining in the failed interface, splats landing in large pores had higher adhesion strength given influencing factors such as pull out of ceramic grains or $\mathrm{Ti}$ from the pores. The amount of Ti remaining on the substrate following splat adhesion testing influences adhesion strength on all $\mathrm{Al}_{2} \mathrm{O}_{3}$ substrates.

The failed $\mathrm{Ti} / \mathrm{SiC}$ interface showed very little evidence of bonding in localized areas. A significant amount of Ti powder rebounded from the substrate leaving rings with fine traces of $\mathrm{Ti}$ on the $\mathrm{SiC}$ substrate. No traces of rebound were observed on $\mathrm{Al}_{2} \mathrm{O}_{3}$ substrates. While ASI led to a continuous ring of Ti for many splats on $\mathrm{Al}_{2} \mathrm{O}_{3}(0.16)$, it led to weak localized bonds in the $\mathrm{Ti} / \mathrm{SiC}$ interface. 
Acknowledgments The authors gratefully acknowledge the assistance of Dr. Phuong Vo and Jean-Francois Alarie at the McGill Aerospace Materials and Alloys Design Center (MAMADC) for technical support with the cold spray equipment. They also, thank Thomas Schmitt and Jolanta Sapieha for technical support and access to the scratch tester. This project would also not have been possible without the financial support from the Natural Science and Engineering Research Council (NSERC) Strategic Grants Program. 


\section{References}

1. A. Papyrin, Cold Spray Technology. Elsevier, Amsterdam, The Netherlands, 2007.

2. J. Villafuerte, Modern Cold Spray : Materials, Process, and Applications. Springer, Windsor, Ontario, Canada, 2015.

3. H. Assadi, F. Gärtner, T. Stoltenhoff, and H. Kreye, Bonding Mechanism in Cold Gas Spraying, Acta Mater., 2003, 51(15), p 4379-4394

4. H. Assadi, T. Schmidt, H. Richter, J. O. Kliemann, K. Binder, F. Gärtner, T. Klassen, and H. Kreye, On Parameter Selection in Cold Spraying, J. Therm. Spray Technol., 2011, 20(6), p 11611176

5. M. Grujicic, C. L. Zhao, W. S. De Rosset, and D. Helfritch, Adiabatic Shear Instability Based Mechanism for Particles/Substrate Bonding in the Cold-Gas Dynamic-Spray Process, Mater. Des., 2004, 25(8), p 681-688

6. A. Moridi, S. M. Hassani-Gangaraj, M. Guagliano, and M. Dao, Cold Spray Coating: Review of Material Systems and Future Perspectives, Surf. Eng., 2014, 30(6), p 369-395

7. H. Y. Lee, Y. H. Yu, Y. C. Lee, Y. P. Hong, and K. H. Ko, Cold Spray of Sic and Al2o3 with Soft Metal Incorporation: A Technical Contribution, J. Therm. Spray Technol., 2004, 13(2), p 184189

8. H. Assadi, H. Kreye, F. Gärtner, and T. Klassen, Cold Spraying - a Materials Perspective, Acta Mater., 2016, 116, p 382-407

9. R. R. Chromik, S. A. Alidokht, J. M. Shockley, and Y. Zhang, Tribological Coatings Prepared by Cold Spray, Cold-Spray Coatings: Recent Trends and Future Perspectives. P. Cavaliere, Springer International Publishing, Cham, Switzerland, 2018, p 321-348

10. K.-R. Donner, F. Gaertner, and T. Klassen, Metallization of Thin Al2o3 Layers in Power Electronics Using Cold Gas Spraying, J. Therm. Spray Technol., 2011, 20(1-2), p 299-306

11. K. R. Ernst, J. Braeutigam, F. Gaertner, and T. Klassen, Effect of Substrate Temperature on Cold-Gas-Sprayed Coatings on Ceramic Substrates, J. Therm. Spray Technol., 2013, 22(2-3), p $422-432$

12. B. Wielage, T. Grund, C. Rupprecht, and S. Kuemmel, New Method for Producing Power Electronic Circuit Boards by Cold-Gas Spraying and Investigation of Adhesion Mechanisms, Surf. Coat. Technol., 2010, 205(4), p 1115-1118

13. C. Wüstefeld, D. Rafaja, M. Motylenko, C. Ullrich, R. Drehmann, T. Grund, T. Lampke, and B. Wielage, Local Heteroepitaxy as an Adhesion Mechanism in Aluminium Coatings Cold Gas Sprayed on Aln Substrates, Acta Mater., 2017, 128, p 418-427

14. L. L. Hench, and S. M. Best, Ceramics, Glasses, and Glass-Ceramics: Basic Principles, Biomaterials Science, 3rd ed., B. D. Ratner, A. S. Hoffman, F. J. Schoen and J. E. Lemons, Academic Press, Kidlington, Oxford, 2013, p 128-151

15. J. B. Brunski, Metals: Basic Principles, Biomaterials Science, 3rd ed., B. D. Ratner, A. S. Hoffman, F. J. Schoen and J. E. Lemons, Academic Press, Kidlington, Oxford, 2013, p 111-119

16. H. Lee, and K. Ko, Effect of Sic Particle Size on Cold Sprayed Al-Sic Composite Coatings, Surf. Eng., 2009, 25(8), p 606-611

17. D. Rafaja, T. Schucknecht, V. Klemm, A. Paul, and H. Berek, Microstructural Characterisation of Titanium Coatings Deposited Using Cold Gas Spraying on A12o3 Substrates, Surf. Coat. Technol., 2009, 203(20-21), p 3206-3213 
18. R. Drehmann, T. Grund, T. Lampke, B. Wielage, K. Manygoats, T. Schucknecht, and D. Rafaja, Interface Characterization and Bonding Mechanisms of Cold Gas-Sprayed Al Coatings on Ceramic Substrates, J. Therm. Spray Technol., 2015, 24(1-2), p 92-99

19. R. Drehmann, T. Grund, T. Lampke, B. Wielage, K. Manygoats, T. Schucknecht, and D. Rafaja, Splat Formation and Adhesion Mechanisms of Cold Gas-Sprayed Al Coatings on Al2o3 Substrates, J. Therm. Spray Technol., 2014, 23(1-2), p 68-75

20. K. H. Ko, J. O. Choi, and H. Lee, The Interfacial Restructuring to Amorphous: A New Adhesion Mechanism of Cold-Sprayed Coatings, Mater. Lett., 2016, 175, p 13-15

21. S. Kümmel, T. Grund, P. Löschner, and B. Wielage, Influence of Deposition Conditions and Heat Treatment on Tensile Strength of Cold Spray Aluminium Coatings on Al2o3 and Aln Substrates, Thermal Spray 2011: Proceedings of the International Thermal Spray Conference, September 26-29, 2011, (Hamburg, Germany), DSV, 2011, p 1130-1135

22. R. Drehmann, T. Grund, T. Lampke, B. Wielage, C. Wüstefeld, M. Motylenko, and D. Rafaja, Essential Factors Influencing the Bonding Strength of Cold-Sprayed Aluminum Coatings on Ceramic Substrates, J. Therm. Spray Technol., 2018, 27(3), p 446-455

23. K. H. Kim, M. Watanabe, and S. Kuroda, Bonding Mechanisms of Thermally Softened Metallic Powder Particles and Substrates Impacted at High Velocity, Surf. Coat. Technol., 2010, 204(14), p 2175-2180

24. A. Sova, V. F. Kosarev, A. Papyrin, and I. Smurov, Effect of Ceramic Particle Velocity on Cold Spray Deposition of Metal-Ceramic Coatings, J. Therm. Spray Technol., 2011, 20(1-2), p 285-291

25. A. Sova, A. Papyrin, and I. Smurov, Influence of Ceramic Powder Size on Process of Cermet Coating Formation by Cold Spray, J. Therm. Spray Technol., 2009, 18(4), p 633-641

26. S. V. Klinkov, and V. F. Kosarev, Cold Spraying Activation Using an Abrasive Admixture, J. Therm. Spray Technol., 2012, 21(5), p 1046-1053

27. R. R. Chromik, D. Goldbaum, J. M. Shockley, S. Yue, E. Irissou, J. G. Legoux, and N. X. Randall, Modified Ball Bond Shear Test for Determination of Adhesion Strength of Cold Spray Splats, Surf. Coat. Technol., 2010, 205(5), p 1409-1414

28. D. Goldbaum, J. M. Shockley, R. R. Chromik, A. Rezaeian, S. Yue, J. G. Legoux, and E. Irissou, The Effect of Deposition Conditions on Adhesion Strength of Ti and Ti6al4v Cold Spray Splats, J. Therm. Spray Technol., 2012, 21(2), p 288-303

29. "Sintered Metal Materials, Excluding Hardmetals - Measurement of Surface Roughness," ISO 23519:2010, International Organization for Standardization ISO, 2010

30. K. Kim, M. Watanabe, and S. Kuroda, Thermal Softening Effect on the Deposition Efficiency and Microstructure of Warm Sprayed Metallic Powder, Scr. Mater., 2009, 60(8), p 710-713

31. K. Yamada, and M. Mohri, Properties and Applications of Silicon Carbide Ceramics, Silicon Carbide Ceramics--1 : Fundamental and Solid Reaction. S. Sömiya and Y. Inomata, Elsevier, London, England, 1991, p 13-44

32. T. Schmidt, F. Gärtner, H. Assadi, and H. Kreye, Development of a Generalized Parameter Window for Cold Spray Deposition, Acta Mater., 2006, 54(3), p 729-742

33. B. Samareh, and A. Dolatabadi, A Three-Dimensional Analysis of the Cold Spray Process: The Effects of Substrate Location and Shape, J. Therm. Spray Technol., 2007, 16(5-6), p 634-642 34. T. Hussain, Cold Spraying of Titanium: A Review of Bonding Mechanisms, Microstructure and Properties, Key Eng. Mater., 2013, 533, p 53-90

35. G. Bae, Y. Xiong, S. Kumar, K. Kang, and C. Lee, General Aspects of Interface Bonding in Kinetic Sprayed Coatings, Acta Mater., 2008, 56(17), p 4858-4868 
36. M. V. Vidaller, A. List, F. Gaertner, T. Klassen, S. Dosta, and J. M. Guilemany, Single Impact Bonding of Cold Sprayed Ti-6al-4v Powders on Different Substrates, J. Therm. Spray Technol., 2015, 24(4), p 644-658

37. T. Schmidt, F. Gartner, H. Assadi, and H. Kreye, Development of a Generalized Parameter Window for Cold Spray Deposition, Acta Mater., 2006, 54(3), p 729-742

38. T. Akatsu, N. Hosoda, T. Suga, and M. Rühle, Atomic Structure of Al/Al Interface Formed by Surface Activated Bonding, J. Mater. Sci., 1999, 34(17), p 4133-4139

39. M. Aghasibeig, H. Monajatizadeh, P. Bocher, A. Dolatabadi, R. Wuthrich, and C. Moreau, Cold Spray as a Novel Method for Development of Nickel Electrode Coatings for Hydrogen Production, Int. J. Hydrogen Energy, 2016, 41(1), p 227-238

40. T. Hussain, D. G. McCartney, P. H. Shipway, and D. Zhang, Bonding Mechanisms in Cold Spraying: The Contributions of Metallurgical and Mechanical Components, J. Therm. Spray Technol., 2009, 18(3), p 364-379

41. S. Kumar, G. Bae, and C. Lee, Influence of Substrate Roughness on Bonding Mechanism in Cold Spray, Surf. Coat. Technol., 2016, 304, p 592-605 